\title{
Nursing students' experiences of multiprofessional simulation education
}

\author{
Mari Helena Salminen-Tuomaala*1, Pasi Jaskari ${ }^{2}$ \\ ${ }^{1}$ Seinäjoki University of Applied Sciences, School of Health Care and Social Work, Finland \\ ${ }^{2}$ Seinäjoki Vocational Education Centre, Seinäjoki, Finland
}

Received: October 16, 2017

Accepted: November 24, 2017 Online Published: December 13, 2017

DOI: $10.5430 /$ cns.v6n2p17

URL: https://doi.org/10.5430/cns.v6n2p17

\begin{abstract}
Objective: To describe how nurse students specializing in acute nursing care and practical nurse students specializing in emergency care experienced a joint simulation education program and the usefulness of simulation education in general.

Methods: Data were collected using a questionnaire from nurse and practical nurse students $(\mathrm{N}=21)$, who had together undertaken a multiprofessional simulation-based course. Quantitative data was analyzed using statistical methods, whereas inductive content analysis was conducted to analyze qualitative data.

Results: Respondents found simulation education useful for the development of theoretical and practical skills and interaction skills. Shared competence was appreciated. It consisted of sharing one's knowledge, learning from others, learning together and learning teamwork skills. Respondents regarded multiprofessional simulation education as an effective method in learning how to deal with acute, recurrent or infrequent situations. Simulated learning also provided respondents with explicit experience of multiprofessional collaboration in emergency care and facilitated their learning of collegiality with help of constructive feedback. Conclusions: Simulation education can promote nursing students' technical and non-technical skills and help students form a clearer perception of multiprofessional collaboration. Careful planning and timing of joint simulated learning sessions is recommended.
\end{abstract}

Key Words: Nurse, Practical nurse, Student, Learning method, Simulation

\section{INTRODUCTION}

A two-day simulation educational program was arranged jointly for nurse students specializing in acute nursing care and for practical nurse students specializing in emergency care by a university of applied sciences and by a vocational education center in Finland in April 2017. The topic was "Care of trauma patients in out-of hospital emergency care and in the emergency department". The simulation education program involved 9 registered nurse students and 14 practical nurse students. In Finland, registered nurses are trained in universities of applied sciences. The length of the program is 3.5 years and the graduates obtain a Bachelor's degree. Practical nurses (or enrolled nurses) are nurses with a more limited scope of practice. Depending on their educational background, they study 2-3 years to obtain a vocational qualification.

This was the first simulation education event arranged jointly by the two educational institutions, so it served as a pilot experiment. There are plans to later include medical students in similar education events. Workshops and full scale simula-

\footnotetext{
* Correspondence: Mari Helena Salminen-Tuomaala; Email: mari.salminen-tuomaala@seamk.fi; Address: Seinäjoki University of Applied Sciences, School of Health Care and Social Work, Finland.
} 
tions were used as learning methods. The students prepared themselves for the simulation education according to their learning objectives, which were both technical (assessment and care of trauma patients) and non-technical (cooperation, interaction and communication). A home setting and an emergency department were prepared as learning environments and one of the teachers assumed the role of the patient. Another teacher played the role of a doctor at the emergency department, and one teacher was a consulting doctor on the telephone. Three students participated in each scenario. All scenarios were followed by group debriefing sessions, in which students first reflected on their performance and secondly received constructive feedback on the technical and non-technical aspects of their performance. Feedback was first provided by peer students and then by the teachers.

This study reports on the students' experiences of simulation education. It is part of a larger research project, whose purpose is to create a multiprofessional simulated learning environment for a network of partners.

\section{BACKGROUND}

Today's professionals are faced with increasingly complex health needs of the population. A combination of interdisciplinary knowledge and skills is required to ensure that the care is patient-centered, holistic and of the highest possible quality. ${ }^{[1]}$

Acute nursing care is characterized by dynamic situations and the demand to recognize rapid changes in the patients' conditions. Effective and seamless teamwork and unambiguous communication are necessary to manage the situations. ${ }^{[2-4]}$ The quality of team work also affects the patient's experience of the care quality. ${ }^{[5]}$ Team members may possess different skills, qualifications and work histories, ${ }^{[6,7]}$ so it would be beneficial, if representatives of various professional groups practiced the management of acute situations together, in multiprofessional teams. This would help them become better aware of each other's competence and scope of responsibility. ${ }^{[3]}$ Decision-making skills, especially, should be practiced to effectively deal with acute situations. ${ }^{[8]}$

Multiprofessional education, also called interprofessional education, involves representatives from two or more professions learning together and from each other in a collaborative learning environment with the aim of improving the quality of patient care. ${ }^{[9]}$ In this study, the term multiprofessional refers to the two nursing professions, which in Finland are quite distinct and based on different curricula and role definitions. The Bachelor's program specializing in acute nursing care provides competence in the management of emergency situations both in and out of hospital, whereas the practical nurse qualification, with specialization in emergency care, primarily prepares students for out-of-hospital service. Compared to practical nurses, registered nurses with a Bachelor's degree have a more extensive theoretical and practical education. Their scope of practice is wider and they are expected to assume greater responsibility.

Multiprofessional education can increase team members' mutual appreciation. In team work, the members' individual characteristics, personalities, attitudes and theoretical and practical competencies come together, influencing the overall outcome. Learning together can improve participants' technical and non-technical skills, both of which are of consequence in terms of the outcome. The latter include for example situational awareness and stress resistance. ${ }^{[1,10-17]}$ Participants also need to become aware of the limits of their competence. Multiprofessional collaboration does not just "happen" when people start working together; it requires interaction skills, trust and an open atmosphere. In addition, participants need to reach a common understanding of the aims of their action. ${ }^{[18]}$ Research indicates that many of these competencies can be effectively practiced using action-based learning methods..$^{[1,10-17]}$

Simulation is a safe method of practicing multiprofessional teamwork in a controlled environment. The learning takes place in nearly authentic clinical situations, according to carefully planned learning aims and contents. Simulation pedagogy aims at immersive, action-based and experiential learning. In nursing it can be useful in practicing various patient care situations and in developing occupational safety and management skills, among other things. ${ }^{[19]}$ Simulation pedagogy also aims at seeking a shared understanding of the challenges and solutions in various clinical situations. ${ }^{[7,20]}$

Simulation-based courses can focus on a specific patient group, illness or care setting. ${ }^{[21]}$ Simulated learning starts with a preparation phase, in which the content and learning objectives are set for a scenario and described to participants. Learner and observer roles are also assigned. The next phase, the actual simulation activity, is always followed by reflection. Facilitators, learners and observers discuss and reflect on the proceedings. ${ }^{[22]}$ This discussion or debriefing combines constructive feedback and each learner's personal reflection. The entire process can promote students' professional development effectively through profound learning experiences. A positive, encouraging atmosphere is essential to enable open interaction between participants. ${ }^{[5,7,23]}$

To sum up, all the dynamic interaction, collaboration, coordination and management processes occurring in teams have an effect on patient safety and quality, and also on worker satisfaction and feelings of success. ${ }^{[10-13]}$ In consequence, 
teamwork is one of the essential skills that can and should be practiced to promote collaboration and reduce errors. ${ }^{[23,24]}$ Successful multiprofessional teamwork has the benefits of combining skills and knowledge, crossing boundaries and creating effective networks to develop a more client-centered approach. ${ }^{[25]}$ Multiprofessional simulation-based courses offer an opportunity to practice all these skills.

\section{Methods}

The study is an evaluative survey based on a selfadministered questionnaire. The purpose of the study is to describe how nurse students specializing in acute nursing care and practical nurse students specializing in emergency care experienced the jointly arranged simulation education program and the usefulness of simulation education in general. The study aims at producing knowledge that can be used by a network of partners to promote collaboration and the development of simulation education.

\subsection{Research questions}

The research questions were:

- What kind of knowledge do nurse and practical nurse students have of simulation as a learning method?

- What kind of knowledge do nurse and practical nurse students have of simulated learning environments?

- What kind of experiences do nurse and practical nurse students have of multiprofessional simulation education?

- In what way is simulation education useful?

\subsection{Target group and data collection}

The target group involved: (1) nurse students studying for a Bachelor degree and specializing in acute nursing care at a university of applied sciences and (2) practical nurse students studying for a vocational qualification and specializing in emergency care at a vocational education center in Finland. Both groups of students were near to graduation and they had together taken part in a 2-day simulation education program.

Students answered a questionnaire in the classroom in May 2017. They were orally told that participation was voluntary, they could respond anonymously and their assessment or grading would not in any way be affected by their responses. The cover letter attached to the questionnaire also included relevant research ethical information. Students had 30 minutes time to respond. Respondents were 7 nurse students and 14 practical nurse students.

\subsection{The instrument}

The questionnaire, developed for this purpose, was based on a systematic literature review. It contained both quantitative

Published by Sciedu Press and qualitative items. There were 18 statistical questions, in 16 of which the Likert scale was used. The background questions concerned respondents' gender, age and profession. Quantifiable Likert-scale questions were used to collect as objective and comparable data as possible. Respondents were requested to rate their knowledge of simulated learning environments and of simulation as a learning method using a five-point scale (good, quite good, moderate, quite weak, weak). Similarly, they were instructed to rate the usefulness of simulation education from the perspective of theoretical, practical and interaction competence on a five-point scale. To ensure that no significant experiences are excluded, the questionnaire further included three open questions on students' experiences of multiprofessional simulation education and its usefulness. This article reports on both the quantitative and qualitative results.

\subsection{Data analysis}

\subsubsection{Statistical analysis}

SPSS Statistics for Windows 23 was used for statistical analysis. Respondents were classified into two groups according to their age: the 20-year-old or younger students $(57 \%)$ and the over 20-year-old students (43\%). There were 19 women and 2 men. Frequencies, percentages and means are used to describe statistical data.

\subsubsection{Inductive content analysis}

Responses to the open questions were analyzed using inductive content analysis. ${ }^{[26,27]}$ The analysis started by reading through the text data several times. The transcribed material was searched through to discover all sentences or other units forming a thought that seemed to represent an answer to any of the research questions. This data was collected in word files as reduced expressions, which retained the original core idea of the sentence or other unit. Expressions with similar contents were grouped under sub-categories, which were given appropriate names. The sub-categories were further grouped into main categories. Throughout the analysis, the investigator repeatedly returned to the original expressions to ensure correct interpretation.

\subsection{Research ethics}

The research topic is ethically justified and important, because the educational authorities in Finland are currently striving to narrow the gap between different levels of education. The aim is to facilitate transfer from vocational qualifications to Bachelor studies in universities of applied sciences. ${ }^{[28]}$ Arranging joint courses, for example for nurse and practical nurse students together, is one effort to reach this aim. The importance of the multiprofessional approach and the need for further research knowledge has been dis- 
cussed for decades. ${ }^{[29]}$ In Finland, the topic concerns a relatively large network of users. The study results can be used when developing joint simulation-based programs for nurse and practical nurse students, but also when planning multiprofessional continuing education programs for nursing and medical staff or for other networks of partners.

The ethical principles of the Helsinki Declaration ${ }^{[30]}$ were observed throughout the study. Any ethical decisions made are based on responsible conduct of research as defined in the guidelines of the National Advisory Board on Research Integrity. ${ }^{[31]}$ Participation in the study was voluntary and based on respondents' informed consent. Respondents answered anonymously. ${ }^{[32]}$

\subsection{Reliability}

In regard to quantitative questions, the study was assessed for its reliability and validity. The response rate of $91 \%$ can be considered good, ${ }^{[33]}$ but the limited number of respondents limits the generalizality of the study. The results can only be considered indicative. As regard the qualitative items, the criteria of credibility, confirmability, reflexivity and transferability were used to evaluate the study. ${ }^{[34]}$ Credibility was ensured by returning to respondents' original expressions several times during the analysis and by integrating direct quotations into the text. Confirmability was increased by careful analysis and reporting. Credibility and confirmability were also enhanced by the use of tables illustrating the analytical process and the results. Reflexivity refers to the fact that researchers should be aware of their background and its influence on planning, conducting and analyzing research. ${ }^{\text {[25] }}$ Both investigators in this study have a long work history in nursing and nursing education, which may have caused bias in interpreting the results. On the other hand, the investigators' experience of simulation education and application of simulation pedagogy have increased their pre-understanding of the phenomenon under study. This knowledge facilitated the analysis. Still, special attention was paid to maintaining the data-driven approach. ${ }^{[35]}$ Finally, investigators reflected on the transferability of the results. It would seem that the results can be widely used in further planning and development of multiprofessional simulation education programs.

\section{Results}

\subsection{Demographic data}

The response rate was $91 \%$. Participants were 21 students; 7 nurse students and 14 practical nurse students. The majority of them, 19 were women and 2 were men. Respondents' age varied between 18 and 30 years. No comparative analysis was conducted between nurse and practical nurse students, or between female and male respondents because of the limited number of participants and to ensure anonymity.

\subsection{Quantitative findings}

\subsubsection{The quantitative results of the study are depicted in Tables 1 and 2}

Students had good knowledge of simulation as a learning method. One third (33\%) of the respondents rated their knowledge as good and $48 \%$ as quite good. A minority found that their knowledge was moderate $(14 \%)$ or weak $(5 \%)$. The results were similar for students' knowledge of simulated learning environments. The majority of the respondents said that their knowledge was good $(48 \%)$ or quite good $(38 \%)$, whereas $10 \%$ rated their knowledge as moderate and $4 \%$ as weak.

Table 1. Students' knowledge of simulation as a learning method and of simulated learning environments

\begin{tabular}{llllll}
\hline Students' knowledge of simulation & Good & Quite good & Moderate & Quite weak & Weak \\
\hline Students' knowledge of simulation as a learning method & $33 \%$ & $48 \%$ & $14 \%$ & $0 \%$ & $5 \%$ \\
Students' knowledge of simulated learning environments & $48 \%$ & $38 \%$ & $10 \%$ & $0 \%$ & $10 \%$ \\
\hline
\end{tabular}

\subsubsection{Usefulness of simulation education in promoting theoretical and practical competence}

Both nurse and practical nurse students agreed that simulation was a useful learning method. A clear majority (67\%) of the respondents said that simulation education had greatly promoted their learning. In addition, $19 \%$ found that simulation had promoted their learning quite much. Only $4 \%$ of the students chose the option "quite little" and $10 \%$ said that simulation had been of little use for them.

The majority or $67 \%$ of the respondents agreed that simulation had greatly promoted their theoretical competence.
Furthermore, $19 \%$ reported that simulation had enhanced their theoretical competence quite much. The option "moderately" was selected by $10 \%$ of the respondents. Only one respondent experienced that simulation had had little effect on her or his theoretical competence.

Simulation was found especially useful for the development of practical competence, with $81 \%$ of the students stating that their practical competence had been greatly promoted and $14 \%$ saying that their competence had been promoted quite much. The remaining 5\% reported that simulation had not much affected their practical competence. 
Table 2. Students' perception of the usefulness of simulation education

\begin{tabular}{|c|c|c|c|c|c|}
\hline Usefulness of simulation education & Greatly & Quite much & Moderately & Quite little & Little \\
\hline Simulation education promoted my learning & $67 \%$ & $19 \%$ & $0 \%$ & $4 \%$ & $10 \%$ \\
\hline Simulation education promoted my theoretical competence & $67 \%$ & $19 \%$ & $10 \%$ & $0 \%$ & $4 \%$ \\
\hline Simulation education promoted my practical competence & $81 \%$ & $14 \%$ & $0 \%$ & $0 \%$ & $5 \%$ \\
\hline $\begin{array}{l}\text { Constructive feedback promoted my professional } \\
\text { competence }\end{array}$ & $67 \%$ & $24 \%$ & $5 \%$ & $0 \%$ & $4 \%$ \\
\hline Simulation education promoted my interaction skills & $86 \%$ & $10 \%$ & $0 \%$ & $4 \%$ & $0 \%$ \\
\hline Simulation education strengthened my teamwork skills & $81 \%$ & $14 \%$ & $0 \%$ & $0 \%$ & $5 \%$ \\
\hline Simulation education promoted my management skills & $67 \%$ & $24 \%$ & $5 \%$ & $0 \%$ & $4 \%$ \\
\hline Simulation education promoted my supervisory skills & $67 \%$ & $24 \%$ & $5 \%$ & $0 \%$ & $4 \%$ \\
\hline $\begin{array}{l}\text { Simulation education promoted my skills in encountering and } \\
\text { supporting family members }\end{array}$ & $48 \%$ & $19 \%$ & $19 \%$ & $5 \%$ & $9 \%$ \\
\hline $\begin{array}{l}\text { Simulation education promoted my logical reporting and } \\
\text { clinical communication }\end{array}$ & $71 \%$ & $19 \%$ & $0 \%$ & $0 \%$ & $10 \%$ \\
\hline $\begin{array}{l}\text { Simulation education was useful in learning to deal with } \\
\text { acute situations }\end{array}$ & $62 \%$ & $24 \%$ & $10 \%$ & $0 \%$ & $4 \%$ \\
\hline $\begin{array}{l}\text { Simulation education was useful in frequently occurring } \\
\text { situations }\end{array}$ & $48 \%$ & $43 \%$ & $5 \%$ & $0 \%$ & $4 \%$ \\
\hline $\begin{array}{l}\text { Simulation education was useful in practicing dealing with } \\
\text { infrequent situations }\end{array}$ & $52 \%$ & $29 \%$ & $10 \%$ & $0 \%$ & $9 \%$ \\
\hline $\begin{array}{l}\text { Simulation education was useful in addressing ethically } \\
\text { challenging situations }\end{array}$ & $57 \%$ & $14 \%$ & $10 \%$ & $0 \%$ & $19 \%$ \\
\hline
\end{tabular}

The students were also requested to rate the importance of feedback following simulation. The majority or $67 \%$ of the students agreed that constructive feedback had greatly promoted their professional competence. Further $24 \%$ found that the feedback had been quite useful, but $9 \%$ said that the feedback had been of little use.

\subsubsection{Usefulness of simulation education in promoting various individual skills}

The results further revealed that a strong majority of the respondents $(86 \%)$ found simulation-based learning very useful for the development of their interaction skills. Additional $10 \%$ of the students stated that simulation had promoted their skills quite much in this respect. The results for the power of simulation pedagogy in strengthening teamwork skills were as follows: very much $81 \%$; quite much $14 \%$ and little $5 \%$.

Management and supervisory skills, very much required in acute care situations, had also been much promoted by simulated learning according to $67 \%$ of the respondents. Almost one fourth of the students $(24 \%)$ found that their management and supervisory skills had strengthened quite much. Of the remaining respondents, $5 \%$ reported moderate and $4 \%$ little improvement in their skills.

The results also indicate that encountering and supporting family members can be practiced through simulation. Respondents rated the value of simulation scenarios for learning to encounter and support family members as follows: very

Published by Sciedu Press useful, 48\%; quite useful, 19\%; moderately useful, 19\%, a little useful (5\%) and of limited use (9\%).

Finally, simulation education seems to provide an opportunity to practice logical reporting and clinical communication and the use of the ISBAR (Identify, Situation, Background, Assessment and Recommendation) method. A clear majority or $71 \%$ of the students rated simulation as very useful in practicing logical reporting and clinical communication. In addition, $19 \%$ of the respondents found the simulation sessions quite useful in this respect. Few students (10\%) selected the option "of limited use".

\subsubsection{Usefulness of simulation education in preparing for various care situations}

Dealing with acute situations requires much knowledge, technical skills and interaction skills. Similar to the other results, most students $(62 \%)$ found that simulation education was very useful in learning to deal with acute nursing situations. The second greatest group (24\%) found simulation quite useful and $10 \%$ of the respondents found it moderately useful. The remaining 4\% did not appreciate simulation as a useful method in learning how to act in acute situations.

Simulation can be used to practice recurring situations. Most students found simulation very useful $(48 \%)$ or quite useful $(43 \%)$ in practicing frequently occurring situations. A minority had experienced moderate $(5 \%)$ or no benefit $(4 \%)$. 
Simulation education also helps prepare for infrequent care situations. Simulation was found very useful by $52 \%$ and quite useful by $29 \%$ of the respondents when practicing dealing with infrequent situations. Again, a minority of the students found the benefit moderate $(10 \%)$ or limited (9\%). Simulation education can also be used when addressing ethically challenging situations. More than half of the students (57\%) found simulation useful or quite useful (14\%) in learning to deal with ethically demanding situations. Few respondents (10\%) felt that simulation was moderately useful. Nearly one fifth (19\%) said that simulation had limited use in learning to deal with ethical challenges.

\subsection{Qualitative findings: Students' experiences of multi- professional simulation education}

As shown in Tables 3 and 4, the content analysis yielded two main categories, Shared competence and Clearer picture of collaboration. In general, students had mostly positive experiences of the simulation education arranged jointly for nurse and practical nurse students. Some students reported that practicing with students other than their peers had made them more nervous. Students also wished that more time and a greater variety of simulation scenarios had been available. The following quotations are from two students.

Table 3. Shared competence

\begin{tabular}{lll}
\hline Sub-category, example & Generic category & Main category \\
\hline - Sharing one's knowledge of drug care and syringe pumps & • Sharing one's knowledge \\
with a practical nurse student & \\
- Teaching a nurse student how to use a stretcher & \\
- Learning from a nurse student how to draw liquid into a & • Learning from others \\
- syringe aseptically & \\
- Getting tips on drug care & \\
- Pondering on a common solution & \\
- Ponder on a transfer technique together & \\
- Good peer teaching & \\
- A good experience of multiprofessional team work & \\
- Multiprofessional interaction & \\
\hline
\end{tabular}

Table 4. Clearer picture of multiprofessional collaboration

\begin{tabular}{lcc}
\hline Exemplar quotes & Sub category & Main category \\
\hline - Telling apart a nurse's and practical nurse's work role & & - Clearer picture of role definitions \\
- Learning to act in a work community & & Clearer picture of \\
- Understanding the role division in field work & & multiprofessional \\
- Seeing things from various perspectives & professions & \\
- Seeing the scope of knowledge and skills in other & - Recognizing competence areas of other \\
professions & & \\
- Promoting collegiality and communication skills & & \\
- Learning collegial action & & \\
- Sharing knowledge mutually & & \\
- Learning to act with appreciation with other professionals & & \\
- Learning multiprofessional interaction & & \\
\hline
\end{tabular}

"A very good experience, just give us more of these joint simulations in the future.” (N1)

"Very pleasant and really useful. The best part was, since you did not know half of the people, the situations became more authentic." (N7)

Students found the multiprofessional sessions more demand- 
ing and challenging than sessions with their peers. They had felt the need to succeed in all the activities involved in simulated learning, but had not found the situation disturbingly competitive. They also stated that similar multiprofessional simulation courses should be offered earlier in the curriculum. They wrote, for example,

"We should have more of these multiprofessional simulations, so that we can get used to multiprofessional collaboration." (N5)

"The situations were different from the ones we had had with our own, familiar group - you did not know the other group. You could challenge yourself and the others." (N6)

\subsubsection{Shared competence}

Students' experiences of multiprofessional simulation education form the main category labeled "shared competence". The four subcategories are discussed below.

The first subcategory, Sharing one's knowledge, was an educational experience, because it meant assuming responsibility for another student's learning. Teaching someone else made students feel more secure about their nursing competence and it promoted their self-confidence. Students stated,

"Really good exercises, sharing my knowledge made me more secure about my skills.” (N3)

"It was nice to share what I know.” (PN5)

The second subcategery, Learning from others, means that the workshops were considered a useful and interesting learning experience. Among other things, practical nurse students learnt from nurse students how to administer drug care and use syringe pumps. Nurse students, in turn, learnt from practical nurse students how to use a stretcher and Virve, which is the authorities' telecommunications network in Finland. For example,

"A really nice experience, you could learn a lot from the other group." (PN4)

"I learnt from a nurse student about aseptic work and drug care." (PN6)

Thirdly, Learning together was experienced as meaningful. Students described how they could experience collegiality and equality despite their different educational backgrounds. They indicated that mutual appreciation and collaboration were required between nursing professionals, irrespective of their qualifications. They also found that reflecting together was often required to reach good decisions. Students' comments involved the following:

"Good peer teaching between nurse and practical nurse students.” (N2)

Published by Sciedu Press
"Pondering on a joint solution during the simulation." (PN9)

"It was great to see how easily two different professional groups were able to cooperate naturally." (N8)

The fourth subcategory was Learning teamwork skills. According to the students, flexible pair and team work are essential in acute nursing. Students mentioned that they found giving space to other students and keeping everyone up to date important in simulation situations. Developing interaction and communication skills was a central element in the learning experience. Students wrote, for example,

"You could learn multiprofessional interaction.” (PN4)

“You got some experience of multiprofessional team work." (N6)

\subsubsection{Clearer picture of multiprofessional collaboration}

Students found multiprofessional simulation education useful, because it gave them a clearer picture of working in pairs in emergency care. The common experience also helped both nurse and practical nurse students better understand their own and each other's role definitions. As shown in Table 4, the main category "Clearer picture of multiprofessional collaboration" was formed of the three subcategories discussed below.

Firstly, obtaining a clearer picture of role definitions was one of the benefits of multiprofessional simulation education experienced by students in this study. The benefit was twofold: on one hand, the education provided students with the necessary theoretical and practical skills, and on the other hand, they became better aware of the scope of their professional responsibility. Multiprofessional simulation education helped students understand how duties and responsibilities were allocated in practical emergency care situations. In the students' own words,

"The division of work between nurses and practical nurses is now clearer to me." (N2)

"It is possible to learn to work together with other professionals.” (N7)

"You learn how to act in a work community. In the field you often work with somebody, who has a different education." (PN13)

Secondly, students learnt to recognize competence areas of other professions. According to the students in this study, multiprofessional simulation education helped them understand what kind of contents were emphasized in the education of the other professional group. Knowing more about the other professionals' skills and knowledge facilitated their understanding of how tasks can be allocated according to the 
care providers' competence and scope of responsibility. As one student put it,

"It is good to know what competence they have in the other profession." (PN8)

Finally, learning collegial collaboration was appreciated. Collegiality was associated with constructive and encouraging interaction and with clear, appreciative feedback from other students during the full scale simulations and workshops. To quote the respondents,

"It promotes collegiality, collaboration skills and interaction." (N1)

\section{"You learn to act in a collegial manner." (N3)}

In addition, students found that multiprofessional simulation education developed their communication and interaction skills. Situational sensitivity, clearer communication and reciprocality were mentioned as further benefits. According to the students,

"It is good to learn interaction. This was another reminder of how important communication is." (PN8)

"Practicing collaboration skills, situational sensitivity, acknowledgement of messages, repetition.” (N7)

\section{DiscuSsion}

Nursing students in this study found multiprofessional simulation education useful for the development of their theoretical, practical and interaction competence. The results confirm earlier conclusions that simulated learning is effective in promoting nursing staff's theory knowledge, skills and attitudes. ${ }^{[36,37]}$ Research has shown that the time spent together with other professionals in a simulated learning environment can lead to sharing of knowledge, skills and values and increase mutual appreciation. ${ }^{[38]}$

Respondents in this study found multiprofessional simulation education especially useful in learning to deal with acute, recurring and infrequent situations. It was further discovered that students appreciated the evolving shared competence, that is, sharing one's knowledge, learning from others, learning together and learning teamwork skills. Students gained a clearer overall picture of multiprofessional collaboration in emergency care services. They learnt to better comprehend their own duties and professional role, but also the competence area, contribution and role of those studying for an affiliated profession. This is inducive to professional growth, because students become better aware of the boundaries of responsibility between various professional groups. Other research has confirmed that simulation-based learning facilitates the understanding of professional roles and responsibil- ities. ${ }^{[23]}$ Joint educational initiatives for nurses and practical nurses working in acute care settings, the use of practice models or frameworks, as well as joint education programs for students of nursing and practical nursing have also been recommended to increase collaboration and understanding of other professionals' roles and contributions. ${ }^{[39]}$

The results indicate that multiprofessional simulation education can foster learning collegial collaboration, provided that feedback is given constructively and equally to all participants. Earlier studies have also revealed the importance of feedback and reflection for professional growth. ${ }^{[12,13,23]} \mathrm{Be}-$ sides simulation, other joint education options can be useful when seeking to promote nurse-practical nurse collaboration in clinical nursing. ${ }^{[39]}$ Focusing on generic competencies besides technical skills in multi and transprofessional education has been suggested to enhance effective team work and patient safety in health services. ${ }^{[40]}$

This study and the multiprofessional simulation education arranged provided valuable experience of joint planning and implementation efforts between educational organizations. Planning the timing of the intervention early enough is essential, as organizations have different time frames. Students should be relatively far advanced in their studies to avoid too challenging learning situations. Too simple simulation exercises, too, can lead to loss of motivation, so careful planning is advisable. All participating organizations should have their representatives contribute to setting learning objectives and other planning. The importance of joint planning sessions has been emphasized in earlier literature as well. ${ }^{[39]}$ It is also advisable to clearly allocate responsibilities for the practical implementation of the educational intervention.

\section{Conclusions}

The results show that multiprofessional simulation education is useful in learning to deal with acute, recurring and infrequent situation. Simulation education facilitates the formation of shared competence, that is sharing knowledge, learning from others, learning together and learning teamwork skill. It helps students form a clearer perception of multiprofessional collaboration in emergency care, even when the term multiprofessional is used for roles within the same discipline (nursing). The study further shows that it is possible to learn collegial collaboration through multiprofessional simulation education, provided that feedback is given constructively and equally. Careful interorganizational planning and timing of joint simulated learning sessions is recommended.

\section{CONFLICTS OF INTEREST DISCLOSURE}

The authors declare they have no conflicts of interest. 


\section{REFERENCES}

[1] Baker DP, Day R, Salas E. Teamwork as an essential component of high reliability organizations. Health Serv Res. 2006; 41: 157798. PMid: 16898980. https://doi.org/10.1111/j.1475-677 $3.2006 .00566 . \mathrm{x}$

[2] Lerner E, Moscati R. The golden hour: scientific fact or medical "urban legend"? Acad Emerg Med. 2001; 8: 758-60. PMid: 11435197. https ://doi.org/10.1111/j.1553-2712.2001.tb00201.x

[3] Flanagan B, Nestel D, Joseph M. Making patient safety the focus: crisis resource management in the undergraduate curriculum. Med Educ. 2004; 38: 56-66. PMid: 14962027. https ://doi.org/10.1 $111 / \mathrm{j} .1365-2923.2004 .01701 . \mathrm{x}$

[4] Mackenzie C, Jeffcott S, Xiao Y. Measuring the impact of time pressure on trauma team task performance. In: Flin R, Mitchell L, editors. Safer surgery: analysing behaviour in the operating theatre. London, UK: Ashgate; 2009. 385-404 p.

[5] Beaubien JM, Baker DP. The use of simulation for training teamwork skills in health care: how low can you go? Qual Saf Health Care. 2004; 13(1): i51-6. PMid: 15465956. https://doi.org/10.113 6/qshc. 2004.009845

[6] Burke CS, Stagl KC, Salas E, et al. Understanding team adaptation: a conceptual analysis and model. J Appl Psychol. 2006; 91: 1189207. PMid: 17100478. https://doi.org/10.1037/0021-9010. 91.6 .1189

[7] Marshall SD, Flanagan B. Simulation-based education for building clinical teams. J Emerg Trauma Shock. 2010; 3(4): 360-8. PMid: 21063559. https://doi.org/10.4103/0974-2700.70750

[8] Undre S, Koutantji M, Sevdalis N, et al. Multidisciplinary crisis simulations: the way forward for training surgical teams. World J Surg. 2007; 31(9): 1843-53. PMid: 17610109. https ://doi.org/10.1 007/s00268-007-9128-x

[9] Barr H, Koppel I, Reeves S, et al. Effective interprofessional education - argument, assumption and evidence. CAIPE London, United Kingdom: Blackwell Publishing; 2005. https ://doi.org/10.1 002/9780470776445

[10] Flin R, Maran N. Identifying and training non-technical skills for teams in acute medicine. Qual Saf Health Care. 2004; 13(Suppl 1): i80-4. PMid: 15465960. https://doi.org/10.1136/qshc. 200 4.009993

[11] Wilson K, Burke CS, Priest H, et al. Promoting health care safety through training high-reliability teams. Qual Saf Health Care. 2005; 14: 303-9. PMid: 16076797. https://doi.org/10.1136/qshc .2004 .010090

[12] LePine JA, Piccolo RF, Jackson CL, et al. A meta-analysis of teamwork processes: tests of a multidimensional model and relationships with team effectiveness criteria. Pers Psychol. 2008; 61: 273-307. https://doi.org/10.1111/j.1744-6570.2008.00114.x

[13] Salas E, Diaz Granados D, Klein C, et al. Does team training improve team performance? A meta-analysis. Hum Factors. 2008; 50(6): 90333. PMid: 19292013. https ://doi .org/10.1518/001872008X 375009

[14] Cook DA. How much evidence does it take? A cumulative metaanalysis of outcomes of simulation-based education. Med Educ. 2014; 48: 750-60. PMid: 25039731. https ://doi.org/10.1111/medu .12473

[15] Braude P, Reedy G, Dasgupta D, et al. Evaluation of a simulation training programme for geriatric medicine. Age Ageing. 2015; 44(4): 677-82. PMid: 25953500. https://doi.org/10.1093/ageing /afv049

[16] Brydges R, Hatala R, Zendejas B, et al. Linking simulation-based educational assessments and patient-related outcomes: a systematic review and meta-analysis. Acad Med. 2015; 90: 246-56. PMid:
25374041. https://doi.org/10.1097/ACM.00000000000005 49

[17] Cheng A, Grant V, Auerbach M. Using simulation to improve patient safety: dawn of a new era. JAMA Pediatr. 2015; 169: 41920. PMid: 25751767. https://doi.org/10.1001/jamapediat rics. 2014.3817

[18] Karila K, Nummenmaa A. Matkalla moniammatillisuuten. Kuvauskohteena päiväkoti [Multiprofessionality in day care center]. Helsinki, Finland: WSOY; 2001.

[19] Hansen J, Bratt M. Competence acquisition using simulated learning experiences: a concept Analysis. Nurs Educ Perspect. 2015; 36(2): 102-7. PMid: 29194134. https : //doi .org/10.5480/13-1198

[20] Mathieu JE, Heffner TS, Goodwin GF, et al. The influence of shared mental models on team process and performance. J Appl Psychol. 2000; 85: 273-83. PMid: 10783543. https://doi.org/10.1037/ 0021-9010.85.2.273

[21] Motola I, Devine LA, Soo Chung H, et al. Simulation in healthcare education: a best evidence practical guide. AMEE Guide No. 82. Med Teach. 2013; 35(10): e1511-30. PMid: 23941678. https://doi.org/10.3109/0142159X.2013.818632

[22] Kettunen N. Simulaatio-opetus terveysalan koulutuksessa. [Simulation in health care education: teachers' experiences in the university of applied sciences, Bachelor's thesis]. Metropolia University of Applied Sciences; 2014. 66 p.

[23] Shapiro JJ, Morey JC, Small SD, et al. Simulation based teamwork training for emergency department staff: does it improve clinical team performance when added to an existing didactic teamwork curriculum? Qual Saf Health Care. 2004; 13: 417-21. PMid: 15576702 https://doi.org/10.1136/qshc.2003.005447

[24] Heimreich R. Managing human error in aviation. Sci Am. 1997; 276(5): 62-7. https://doi.org/10.1038/scientificameric an 0597-62

[25] Isoherranen K. Moniammatillinen yhteistyö [Multiprofessional collaboration]. Vantaa, Finland: WSOY; 2005.

[26] Graneheim UH, Lundman B. Qualitative content analysis in nursing research: concepts, procedures and measures to achieve trustworthiness. Nurse Educa Today. 2004; 24(2): 105-12. PMid: 14769454 https://doi.org/10.1016/j.nedt.2003.10.001

[27] Elo S, Kyngäs H. The qualitative content analysis process. J Adv Nurs. 2008; 36(6): 538-45. https ://doi.org/10.1111/j.1365 $-2648.2007 .04569 . x$

[28] Tutkimus- ja innovaationeuvosto [Research and Innovation Council in Finland]. Uudistava Suomi: tutkimus- ja innovaatiopolitiikan suunta 2015-2020 [Research and innovation policy outline for 2015-2020].2014. Available from: http://minedu.fi/export/s ites/default/OPM/Tiede/tutkimus-_ja_innovaationeu vosto/julkaisut/liitteet/Linjaus2015-2020.pdf

[29] Lincoln YS, Guba EG. Naturalistic inquiry. CA: Sage Publications, Newbury Park; 1985.

[30] World Medical Association Declaration of Helsinki - Ethical principles for medical research involving human subjects. 1964 (last amended in October 2013). Available from: http://www.wma.ne t/en/30publications/10policies/b3/

[31] TENK. [Finnish Advisory Board on Research Integrity] Responsible conduct of research and procedure for handling allegations of misconduct in Finland. Guidelines of the Finnish Advisory Board on Research Integrity. 2012. Available from: http://www.tenk.fi/ sites/tenk.fi/files/HTK_ohje_2012.pdf

[32] Burns N, Grove S. The practice of nursing research. Appraisal, synthesis and generation of evidence. (6th ed.) Missouri: Saunders Elsevier; 2009. 
[33] Baruch Y, Holtom BC. Survey response rate levels and trends in organizational research. Hum Relat. 2008; 61(8): 1139-60. https : //doi.org/10.1177/0018726708094863

[34] Kylmä J, Juvakka T. Laadullinen terveystutkimus [Qualitative health research]. Helsinki, Finland: Edita Prima Oy; 2012.

[35] Holloway I, Wheeler S. Qualitative research in nursing and healthcare. (3rded). West Sussex: Wiley-Blackwell; 2010.

[36] Gaba D. The future of simulation in health care. Qual Saf Health Care. 2004; 13: 2-10. https://doi.org/10.1136/qshc. 2004. 009878

[37] Lateef F. Simulation-based learning: just like the real thing. J Emerg Trauma Shock. 2010; 3(4): 349-52. PMid: 21063557. https://doi.org/10.4103/0974-2700.70743

[38] Bridges D, Davidson R, Odegard P, et al. Interprofessional collaboration: Three best practice models of interprofessional education. Med Educ. Online. 2011; 16: 2035. PMid: 21519399. https://doi.org/10.3402/meo.v16i0.6035

[39] Moore J, Prentice D, Salfi J. A mixed-methods pilot study of the factors that influence collaboration among registered nurses and registered practical nurses in acute care. Clin Nurs Stud. 2017; 5(4): 1-11. https : //doi.org/10.5430/cns.v5n4p1

[40] Frenk J, Chen L, Bhutta ZA, et al. Health professionals for a new century: transforming education to strengthen health systems in an interdependent world. Lancet. 2010; 376: 1923-58. https : //doi .org/10.1016/S0140-6736(10)61854-5 